\title{
KEBIJAKAN PEMILIHAN LOKASI PEMBANGUNAN \\ LUMBUNG PANGAN
}

\section{SITE SELECTION POLICY FOR DEVELOPMENT OF FOOD STORAGE}

\author{
Suroso \\ Kantor Penelitian dan Pengembangan Kabupaten Pati \\ E-mail: suroso_peneliti@yahoo.co.id
}

Naskah Masuk: 23 Mei $2014 \quad$ Naskah Revisi: 26 Mei $2014 \quad$ Naskah Diterima: 5 Juni 2014

\begin{abstract}
Pati Regency is an agricultural region and it is vulnerable to flood disaster so development of food storage to support availability of food is needed. The objective of the research is to analyze the site selection for development of food storage. This research uses descriptive-quantitative approach. This research consists of (1) main food production; and (2) site selection for development of food storage. Data collecting of the research uses the technique of observation in related documents. The research uses descriptive analysis. There are two main findings in the research. Firstly, food production in the area study is 439,371.67 ton. It is $292 \%$ compared to normative need consumption of food so there is 288,901.92 ton of food which is potential to store. Secondly, development of food storage by consideration on food production, access and risk of food will be optimum if it is located in Kayen District.
\end{abstract}

Keywords: development, food storage, policy

\begin{abstract}
ABSTRAK
Kabupaten Pati merupakan daerah agraris dan rentan terkena bencana banjir sehingga pembangunan lumbung pangan untuk menopang ketersediaan cadangan pangan sangat diperlukan. Penelitian ini memiliki tujuan menganalisis pemilihan lokasi pembangunan lumbung pangan. Penelitian ini menggunakan pendekatan deskriptif-kuantitatif. Penelitian ini memiliki 2 variabel: (1) produksi pangan pokok; dan (2) pemilihan lokasi pembangunan lumbung pangan. Pengumpulan data penelitian dilakukan dengan teknik observasi dokumen dinas/instansi terkait. Analisis data dengan analisis deskriptif. Penelitian ini memiliki 2 temuan utama. Pertama, produksi pangan sebesar 439.371,67 ton (292\%) dari kebutuhan normatif konsumsi sehingga kelebihan produksi yang berpotensi untuk disimpan sebanyak 288.901,92 ton (192\%). Kedua, lokasi terbaik untuk pembangunan lumbung pangan dengan pertimbangan produksi pangan, akses jalan dan risiko banjir, paling optimal bila ditempatkan di Kecamatan Kayen.
\end{abstract}

Kata kunci: kebijakan, lumbung pangan, pembangunan 


\section{PENDAHULUAN}

Ketersediaan pangan yang cukup merupakan bagian dari kewajiban negara (pemerintah/pemerintah daerah). World Food Summit yang diselenggarakan FAO tanggal 13-17 November 1996 di Roma, Italia, menghasilkan sejumlah komitmen dari perwakilan negara-negara di dunia (termasuk Indonesia) diantaranya berbunyi: "We will implement policies aimed at eradicating poverty and inequality and improving physical and economic access by all, at all times, to sufficient, nutritionally adequate and safe food and its effective utilization". Artinya, kami akan mengimplementasikan kebijakan yang ditujukan pada penanggulangan kemiskinan dan kesenjangan, serta meningkatkan sarana dan akses ekonomi bagi semua di sepanjang waktu, untuk makanan yang cukup, gizi memadai dan aman serta juga sarana pendukung yang efektif.

Kabupaten Pati sebagai daerah agraris memiliki potensi produksi pangan melebihi kebutuhan konsumsi pangan. Daerah agraris terindikasi pada kontribusi yang dominan dari sektor pertanian dalam PDRB sebesar 35,92\% (BPS Kab. Pati, 2013). Sisi lain daerah ini rentan terkena bencana banjir tahunan. Falak dan Sumarni (2014) menyatakan bahwa ada $9.761 \mathrm{Ha}$ lahan pertanian tergenang banjir dan mengalami puso, dengan kerugian ditaksir Rp 156 miliar. Oleh karena itu, ketersediaan cadangan pangan sangat diperlukan untuk langkah preventif dalam menghadapi problem pangan ketika sebagian kawasan terkepung bencana banjir. Sarana pendukung yang efektif bagi penyediaan pangan diantaranya pembangunan lumbung pangan (tempat penyimpanan pangan).

Pembangunan lumbung pangan dengan lokasi yang tepat sangat berguna untuk penyediaan pangan cadangan bagi masyarakat untuk sepanjang waktu termasuk saat bencana banjir terjadi. Tujuan penelitian ini adalah menganalisis pemilihan lokasi pembangunan lumbung pangan dalam rangka mendukung penyimpanan dan distribusi pangan di Kabupaten Pati.

\section{TINJAUAN PUSTAKA}

\section{Pengertian dan Hak atas Pangan}

Pangan adalah segala sesuatu yang berasal dari sumber hayati produk pertanian, perkebunan, kehutanan, perikanan, peternakan, perairan, dan air, baik yang diolah maupun tidak diolah yang diperuntukkan sebagai makanan atau minuman bagi konsumsi manusia, termasuk bahan tambahan pangan, bahan baku pangan, dan bahan lainnya yang digunakan dalam proses penyiapan, pengolahan, dan/atau pembuatan makanan atau minuman (UU No. 18 Tahun 2012). Pemenuhan hak atas pangan, merupakan salah satu komponen penting untuk menikmati hak hidup sejahtera lahir dan batin. Hak atas pangan diatur dalam UU No. 11 Tahun 2005 tentang Kovenan Internasional tentang Hak-Hak Ekonomi Sosial dan Budaya (International Covenant on Economic, Social And Cultural Rights).

Komite Hak Ekonomi Sosial dan Budaya PBB, dalam Komentar Umum (General Comment) No. 12 Tahun 1999, menyatakan bahwa Hak Atas Pangan yang layak dapat terwujud jika setiap laki-laki, perempuan dan anak-anak, baik secara sendiri maupun dalam komunitas dengan yang lain memiliki akses fisik dan ekonomi setiap saat terhadap pangan yang layak atau sarana-sarana untuk pembeliannya. Negara memiliki kewajiban pokok untuk mengambil langkah penting mengurangi dan meringankan bencana kelaparan termasuk pada saat terjadi bencana alam atau bencana yang lain. Hak atas pangan yang layak mengandung: (a) tersedianya pangan dalam jumlah dan 
kualitas yang mencukupi untuk memenuhi kebutuhan diet individu, bebas dari bahanbahan berbahaya, dan dapat diterima oleh budaya-budaya tertentu; dan b) aksesibilitas dari pangan yang berkelanjutan dan tidak mencampuri penikmatan hak asasi manusia yang lain.

\section{Kewajiban Negara atas Pangan}

Kewajiban Negara atas pangan menurut Komentar Umum (General Comment) Komite Hak Ekonomi Sosial dan Budaya PBB No. 12 Tahun 1999 meliputi: (1) kewajiban utama negara adalah melaksanakan langkah-langkah untuk mencapai perwujudan sepenuhnya hak atas pangan yang layak; (2) negara wajib bergerak secepat mungkin untuk pemenuhan hak atas pangan; (3) negara diwajibkan untuk menjamin setiap orang yang berada dalam wilayah yuridiksinya, memiliki akses kepada pangan pokok minimum yang mencukupi, cukup gizi dan aman, untuk menjamin agar mereka bebas dari kelaparan; (4) hak atas pangan bagi setiap orang, membebankan kewajiban kepada Negara untuk menghormati, melindungi dan memenuhi hak atas pangan tersebut; (5) kewajiban negara untuk memenuhi hak atas pangan, mencakup kewajiban untuk memfasilitasi keterjangkauan pangan dan kewajiban untuk menyediakan pangan; (6) kewajiban menghormati akses terhadap pangan yang layak, mensyaratkan negara untuk tidak mengambil langkah-langkah yang mengakibatkan terhalangnya keterjangkauan terhadap pangan; (7) kewajiban untuk melindungi hak atas pangan mensyaratkan negara untuk melaksanakan langkah-langkah untuk menjamin agar perusahaan atau individu tidak mencabut akses individu kepada pangan yang layak; (8) kewajiban untuk memenuhi, (dalam bentuk memfasilitasi) berarti negara harus terlibat secara proaktif dalam kegiatan-kegiatan yang bertujuan untuk memperkuat akses masyarakat kepada pemanfaatan sumber daya dan sarana-sarana untuk menjamin sumber mata pencaharian mereka, termasuk jaminan pangan; (9) kewajiban untuk memenuhi (dalam bentuk menyediakan) berarti kapan saja seseorang atau kelompok orang tidak dapat menikmati hak atas pangan yang layak karena keadaan diluar kendali mereka, negara wajib memberikan (menyediakan) hak atas pangan secara langsung.

Guna melaksanakan kewajiban negara atas pangan diperlukan perencanaan pangan yang baik. Perencanaan pangan menurut UU No. 18 Tahun 2012, dilakukan untuk merancang penyelenggaraan pangan ke arah kedaulatan pangan, kemandirian pangan, dan ketahanan pangan. Perencanaan pangan harus memperhatikan: pertumbuhan dan sebaran penduduk; (b) kebutuhan konsumsi pangan dan gizi; (c) daya dukung sumber daya alam, teknologi, dan kelestarian lingkungan; (d) pengembangan sumber daya manusia dalam Penyelenggaraan Pangan; (e) kebutuhan sarana dan prasarana Penyelenggaraan Pangan; (f) potensi pangan dan budaya lokal; (g) rencana tata ruang wilayah; dan (h) rencana pembangunan nasional dan daerah.

\section{Pemilihan Lokasi Pembangunan Sarana Publik}

Pembangunan prasarana publik perlu mempertimbangkan faktor lokasi dengan cermat. Kesesuaian suatu lokasi yang diusulkan untuk pembangunan fasilitas tertentu tergantung pada faktor yang dipilih dan dievaluasi yang dikaitkan dengan potensi dampak. Ada berbagai faktor lokasi yang mempengaruhi keputusan pemilihan lokasi. Namun faktor yang kurang penting terhadap pembangunan suatu fasilitas tidak perlu dimasukkan dalam pertimbangan kriteria penilaian (Levine dalam Yang, 1997). 
Model keputusan pemilihan lokasi telah berkembang untuk melakukan evaluasi komparatif lokasi potensial melalui investigasi faktor lokasi dan persyaratan area. Beberapa motode baru telah diterapkan dalam studi pemilihan lokasi untuk pembangunan. Model tersebut diantaranya simulasi model, expert systems, dan jaringan teknologi neural (Benyamin dan Riordan, 1995; Ghosh dan Harche, 1993; Kathawala dan Gholamnezhed, 1987).

Kepentingan relatif faktor lokasi dapat berkembang ketika tahap proses pengambilan keputusan berlangsung (Haigh, 1990). Pada tahap awal identifikasi area geografi yang dipilih, hanya beberapa item prioritas yang dipertimbangkan dalam identifikasi kawasan sesuai kriteria. Ketika tahap pemilihan suatu lokasi, faktor lokasi yang spesifik seperti harga tanah dan akses jalan raya dapat mendominasi pertimbangan.

Keputusan pemilihan lokasi untuk pembangunan suatu fasilitas tergantung determinan kondisi geografis. Pertama, pembuatan persyaratan/kriteria lokasi dan bobot kepentingan relatif. Kedua, kriteria tersebut diaplikasikan pada lokasi-lokasi yang dipertimbangkan, dan lokasi yang kurang berkualifikasi dieliminasi sehingga diperoleh lokasi yang paling sesuai. Dalam hal ini studi kelayakan memilih tujuan dan metodologi. Pada tahap evaluasi, lokasi tertentu dianalisis untuk memperoleh rating lokasi. Pemilihan lokasi merupakan langkah akhir berdasarkan analisis detail lokasi melalui investigasi faktor lokasi (Yang dan Lee, 1997).

\section{METODE PENELITIAN}

Penelitian ini menggunakan pendekatan deskriptif-kuantitatif. Menurut Nawawi (1995), metode deskriptif merupakan prosedur pemecahan masalah dengan cara menerangkan obyek penelitian didasarkan pada fenomena faktual dan usaha menemukan korelasi aspek-aspek yang sedang diteliti. Penelitian ini memiliki 2 variabel: (1) produksi pangan pokok; dan (2) pemilihan lokasi pembangunan lumbung pangan. Pangan pokok dalam studi ini dibatasi pada komoditas: padi, jagung, ubi kayu dan ubi jalar. Komparasi produksi pangan pokok di bawah ini menggunakan rerata produksi yang bersumber dari Dinas Pertanian Kabupaten Pati Tahun 2010, 2011 dan 2012. Pengumpulan data dilakukan dengan teknik observasi dokumen dinas/instansi terkait. Analisis data dengan analisis deskriptif.

\section{HASIL DAN PEMBAHASAN}

\section{Produksi Pangan Pokok}

\section{Produksi Neto Padi dan Beras}

Kondisi produksi padi di setiap kecamatan di Kabupaten Pati sangat bervariasi. Perbedaan produksi di setiap kawasan sangat dipengaruhi oleh kondisi iklim dan sarana irigasi. Pengukuran produksi neto padi menurut Deptan (2007) menggunakan rumus :

$$
\begin{aligned}
\mathrm{R}_{\text {net }}= & \mathrm{P}_{\text {net }} \times \mathrm{C} \\
& \mathrm{P}_{\text {net }}=\mathrm{P}(1-(\mathrm{s}+\mathrm{f}+\mathrm{w})
\end{aligned}
$$

Keterangan :

$$
\begin{array}{ll}
\mathrm{R}_{\text {net }} & =\text { produksi neto beras } \\
\mathrm{P}_{\text {net }} & =\text { produksi neto padi } \\
\mathrm{C} & =\text { faktor konversi beras }(0,632) \\
\mathrm{P} & =\text { produksi padi bruto di kecamatan (i) } \\
\mathrm{S} & =\text { nilai konversi bibit }(0,0088) \\
\mathrm{f} & =\text { nilai konversi pakan }(0,02) \\
\mathrm{w} & =\text { nilai konversi tercecer }(0,054)
\end{array}
$$

Kabupaten Pati memiliki rerata produksi padi bruto (P) sebanyak $573.460,02$ ton. Produksi bersih padi $\left(\mathrm{P}_{\text {net }}\right)$ diperhitungkan setelah produksi bruto dikurangi kebutuhan bibit (s) dengan besaran nilai 0,0088 setara dengan proporsi $(0,88 \%)$, dikurangi keperluan pakan (s) dengan besaran nilai 0,02 setara dengan proporsi $(2 \%)$ dan besar produksi padi yang tercecer $(w)$ dengan nilai 0,054 
setara dengan 5,4\%. Dengan demikian rerata produksi neto padi sebesar 525.977,53 ton.

Ketersediaan beras neto $\left(\mathrm{R}_{\mathrm{net}}\right)$ dapat diperhitungkan dengan produksi neto padi dikalikan dengan nilai konversi 0,632 yang setara dengan $(63,2 \%)$. Bila produksi neto padi di Kabupaten Pati sebesar 525.977,53 ton, produksi beras neto sebesar $332.417,80$ ton. Persebaran produksi padi dan ketersediaan beras ditunjukkan dalam Tabel 1.

Tabel 1.

Produksi Padi dan Beras di Kabupaten Pati

\begin{tabular}{|c|c|c|c|c|c|c|c|c|}
\hline \multirow{3}{*}{ Kecamatan } & \multicolumn{6}{|c|}{ Produksi Padi (ton) } & \multicolumn{2}{|c|}{ Produksi Beras (ton) } \\
\hline & Produksi & $\mathbf{K}$ & Bibit & Pakan & Tercecer & Prod. Net & Konversi & Beras Neto \\
\hline & $\mathbf{P}$ & 1 & $\mathbf{S}$ & $\mathbf{f}$ & $\mathbf{w}$ & $\mathbf{P}_{\text {net }}$ & $\mathbf{C}$ & $\mathbf{R}_{\text {net }}$ \\
\hline Sukolilo & $84.883,51$ & 1 & 0,0088 & 0,02 & 0,054 & $77.855,16$ & 0,632 & $49.204,46$ \\
\hline Kayen & $53.377,59$ & 1 & 0,0088 & 0,02 & 0,054 & $48.957,93$ & 0,632 & $30.941,41$ \\
\hline Tambakromo & $35.375,53$ & 1 & 0,0088 & 0,02 & 0,054 & $32.446,44$ & 0,632 & $20.506,15$ \\
\hline Winong & $30.802,61$ & 1 & 0,0088 & 0,02 & 0,054 & $28.252,15$ & 0,632 & $17.855,36$ \\
\hline Pucakwangi & $36.622,30$ & 1 & 0,0088 & 0,02 & 0,054 & $33.589,97$ & 0,632 & $21.228,86$ \\
\hline Jaken & $28.225,11$ & 1 & 0,0088 & 0,02 & 0,054 & $25.888,07$ & 0,632 & $16.361,26$ \\
\hline Batangan & $15.374,01$ & 1 & 0,0088 & 0,02 & 0,054 & $14.101,04$ & 0,632 & $8.911,86$ \\
\hline Juwana & $8.039,83$ & 1 & 0,0088 & 0,02 & 0,054 & $7.374,13$ & 0,632 & $4.660,45$ \\
\hline Jakenan & $45.800,65$ & 1 & 0,0088 & 0,02 & 0,054 & $42.008,36$ & 0,632 & $26.549,28$ \\
\hline Pati & $23.785,89$ & 1 & 0,0088 & 0,02 & 0,054 & $21.816,42$ & 0,632 & $13.787,98$ \\
\hline Gabus & $41.230,41$ & 1 & 0,0088 & 0,02 & 0,054 & $37.816,53$ & 0,632 & $23.900,05$ \\
\hline Margorejo & $26.205,89$ & 1 & 0,0088 & 0,02 & 0,054 & $24.036,04$ & 0,632 & $15.190,78$ \\
\hline Gembong & $6.608,99$ & 1 & 0,0088 & 0,02 & 0,054 & $6.061,77$ & 0,632 & $3.831,04$ \\
\hline Tlogowungu & $13.957,73$ & 1 & 0,0088 & 0,02 & 0,054 & $12.802,03$ & 0,632 & $8.090,88$ \\
\hline Wedarijaksa & $8.951,30$ & 1 & 0,0088 & 0,02 & 0,054 & $8.210,13$ & 0,632 & $5.188,80$ \\
\hline Trangkil & $8.327,03$ & 1 & 0,0088 & 0,02 & 0,054 & $7.637,55$ & 0,632 & $4.826,93$ \\
\hline Margoyoso & $16.139,29$ & 1 & 0,0088 & 0,02 & 0,054 & $14.802,96$ & 0,632 & $9.355,47$ \\
\hline Gunungwungkal & $13.110,53$ & 1 & 0,0088 & 0,02 & 0,054 & $12.024,98$ & 0,632 & $7.599,79$ \\
\hline Cluwak & $17.208,84$ & 1 & 0,0088 & 0,02 & 0,054 & $15.783,95$ & 0,632 & $9.975,46$ \\
\hline Tayu & $29.088,94$ & 1 & 0,0088 & 0,02 & 0,054 & $26.680,38$ & 0,632 & $16.862,00$ \\
\hline Dukuhseti & $20.046,40$ & 1 & 0,0088 & 0,02 & 0,054 & $18.386,56$ & 0,632 & $11.620,30$ \\
\hline Kabupaten Pati & $573.460,02$ & 1 & 0,0088 & 0,02 & 0,054 & $525.977,53$ & 0,632 & $332.417,80$ \\
\hline
\end{tabular}

Sumber: Pengolahan Data (2013)

\section{Produksi Neto Jagung}

Kondisi produksi jagung antara kecamatan satu dengan kecamatan lainnya tidak sama. Produksi jagung tidak semua digunakan untuk kepentingan pangan. Menurut Deptan (2007), produksi jagung yang disediakan untuk pangan memiliki nilai konversi 0,6 (60\%). Selebihnya untuk keperluan lain yang bukan terkait dengan pangan masyarakat. Ketersediaan pangan terkait dengan produksi jagung dihitung dengan menggunakan rumus :

$\mathrm{M}_{\text {net }}=\mathrm{Mx} \mathrm{C}$

$\mathrm{M}_{\mathrm{kn}}=\mathrm{M}_{\text {net }} \times 0,77$
Keterangan :

$\mathbf{M}_{\text {net }}=$ produksi neto jagung

$\mathrm{C}$ = faktor konversi jagung $(0,6)$

$\mathrm{M}_{\mathrm{kn}}=$ rasio konsumsi normatif kalori jagung

$0,77=$ jagung kalorinya setara 0,77 beras

Produksi neto jagung terkait dengan pangan masyarakat harus dikonversi nilai kalorinya terhadap nilai kalori beras. Nilai rasio konsumsi normatif kalori jagung (ekuivalen) terhadap beras sebesar 0,77 (77\% dari nilai kalori beras).

Kabupaten Pati memiliki produksi bruto jagung (M) sebesar 120.159,69 ton. Jagung yang disediakan untuk pangan 
memiliki nilai konversi 0,6 (60\%), maka produksi jagung bersih yang digunakan untuk pangan sebesar $72.095,81$ ton. Nilai ekuivalensi kalori jagung terhadap beras (kn) 0,77 dari produksi neto, maka kalori jagung yang tersedia sebanding dengan $55.513,78$ ton (beras) yang berasal dari $72.095,81$ ton kali 0,77. Persebaran produksi jagung dan ekuivalensi terhadap beras ditunjukkan pada Tabel 2 .

Tabel 2.

Produksi Jagung dan Ekuivalensi Kalori Beras di Kabupaten Pati

\begin{tabular}{|c|c|c|c|c|c|}
\hline \multirow{2}{*}{ Kecamatan } & $\begin{array}{c}\text { Produksi } \\
\text { Bruto } \\
\end{array}$ & Konversi & $\begin{array}{c}\text { Produksi } \\
\text { Neto }\end{array}$ & $\begin{array}{c}\text { Equivalen } \\
\text { Beras }\end{array}$ & $\begin{array}{c}\text { Kalori } \\
\text { Jagung }\end{array}$ \\
\hline & $\mathbf{M}$ & C & $\mathbf{M}_{\text {net }}$ & kn & $\mathbf{M}_{\mathrm{kn}}$ \\
\hline Sukolilo & $38.308,51$ & 0,6 & $22.985,11$ & 0,77 & $17.698,53$ \\
\hline Kayen & $19.064,78$ & 0,6 & $11.438,87$ & 0,77 & $8.807,93$ \\
\hline Tambakromo & 17.739 .26 & 0,6 & $10.643,56$ & 0,77 & $8.195,54$ \\
\hline Winong & $10.127,79$ & 0,6 & $6.076,67$ & 0,77 & $4.679,04$ \\
\hline Pucakwangi & $9.175,91$ & 0,6 & $5.505,55$ & 0,77 & $4.239,27$ \\
\hline Jaken & $3.679,74$ & 0,6 & $2.207,84$ & 0,77 & $1.700,04$ \\
\hline Batangan & 776,19 & 0,6 & 465,71 & 0,77 & 358,60 \\
\hline Juwana & 61,85 & 0,6 & 37,11 & 0,77 & 28,57 \\
\hline Jakenan & 170,23 & 0,6 & 102,14 & 0,77 & 78,65 \\
\hline Pati & 153,41 & 0,6 & 92,05 & 0,77 & 70,88 \\
\hline Gabus & $1.077,32$ & 0,6 & 646,39 & 0,77 & 497,72 \\
\hline Margorejo & $5.547,86$ & 0,6 & $3.328,72$ & 0,77 & $2.563,11$ \\
\hline Gembong & $5.182,18$ & 0,6 & $3.109,31$ & 0,77 & $2.394,17$ \\
\hline Tlogowungu & $2.867,22$ & 0,6 & $1.720,33$ & 0,77 & $1.324,66$ \\
\hline Wedarijaksa & 332,01 & 0,6 & 199,21 & 0,77 & 153,39 \\
\hline Trangkil & 129,65 & 0,6 & 77,79 & 0,77 & 59,90 \\
\hline Margoyoso & 2,03 & 0,6 & 1,22 & 0,77 & 0,94 \\
\hline Gunungwungkal & $4.777,11$ & 0,6 & $2.866,27$ & 0,77 & $2.207,02$ \\
\hline Cluwak & 652,8 & 0,6 & 391,68 & 0,77 & 301,59 \\
\hline Tayu & 238,53 & 0,6 & 143,12 & 0,77 & 110,20 \\
\hline Dukuhseti & 95,3 & 0,6 & 57,18 & 0,77 & 44,03 \\
\hline Kabupaten Pati & $120.159,69$ & 0,6 & $72.095,81$ & 0,77 & $55.513,78$ \\
\hline
\end{tabular}

Sumber: Pengolahan Data (2013)

\section{Produksi Neto Ubi Kayu dan Ubi Jalar}

Produksi ubi kayu antar kecamatan sangat bervariasi. Produksi ubi kayu yang digunakan untuk kepentingan pangan hanya sebagian. Menurut Deptan (2007), produksi ubi kayu yang disediakan untuk pangan memiliki nilai konversi 0,28 (28\%). Ketersediaan pangan terkait dengan produksi ubi kayu dikalkulasi dengan menggunakan rumus :

$\mathrm{UK}_{\text {net }}=\mathrm{UK} \times \mathrm{C}$

$\mathrm{UK}_{\mathrm{kn}}=\mathrm{UK}_{\mathrm{net}} \times 0,30$

Keterangan :

$\mathrm{UK}_{\text {net }}=$ produksi neto ubi kayu
$\mathrm{UK}=$ produksi bruto ubi kayu

$\mathrm{C}=$ faktor konversi ubi kayu $(0,28)$

$\mathrm{UK}_{\mathrm{kn}}=$ rasio konsumsi normatif kalori ubi kayu

$0,30=$ ubi kayu kalorinya setara 0,30 beras

Produksi neto ubi kayu terkait dengan pangan masyarakat harus dikonversi nilai kalorinya terhadap nilai kalori beras. Nilai rasio konsumsi normatif kalori ubi kayu (ekuivalen) terhadap beras sebesar 0,30 (30\% dari nilai kalori beras).

Produksi ubi kayu bruto (UK) di Kabupaten Pati sebesar 611.584,75 ton. Ubi kayu yang digunakan untuk pangan 
memiliki nilai konversi 0,28 (28\%), maka produksi ubi kayu bersih (neto) yang digunakan untuk pangan di daerah ini sebesar 171.243,73 ton dan nilai ekuivalensi kalori beras sebesar 51.373,12 ton yang berasal dari $171.243,73$ ton kali 0,30. Distribusi produksi dan ekuivalensi kalori beras ditunjukkan Tabel 3.

Tabel 3.

Equivalensi Kalori Produksi Ubi Kayu dan Ubi Jalar

\begin{tabular}{|c|c|c|c|c|c|c|}
\hline \multirow{3}{*}{ Kecamatan } & \multicolumn{3}{|c|}{ Produksi Ubi Kayu (ton) } & \multicolumn{3}{|c|}{ Produksi Ubi Jalar } \\
\hline & $\begin{array}{l}\text { Produksi } \\
\text { Bruto }\end{array}$ & $\begin{array}{l}\text { Produksi } \\
\text { Neto }\end{array}$ & $\begin{array}{c}\text { Equivalen } \\
\text { Kalori (beras) }\end{array}$ & $\begin{array}{l}\text { Produksi } \\
\text { Bruto }\end{array}$ & $\begin{array}{l}\text { Produksi } \\
\text { Neto }\end{array}$ & $\begin{array}{c}\text { Equivalen } \\
\text { Kalori }\end{array}$ \\
\hline & (UK) & $\mathbf{U K}_{\text {net }}$ & $\mathbf{U k}_{\mathbf{k n}}$ & (UJ) & $\mathbf{U} \mathbf{J}_{\text {net }}$ & $\mathbf{U k}_{\mathbf{k n}}$ \\
\hline Sukolilo & $7.635,39$ & $2.137,91$ & 641.37 & 0,00 & 0,00 & 0,00 \\
\hline Kayen & $2.554,81$ & 715,35 & 214.60 & 110,64 & 15,49 & 4,49 \\
\hline Tambakromo & $1.711,63$ & 479,26 & 143.78 & 15,81 & 2,21 & 0,64 \\
\hline Winong & $1.819,94$ & 509,58 & 152.87 & 841,06 & 117,75 & 34,15 \\
\hline Pucakwangi & $3.648,60$ & $1.021,61$ & 306.48 & 60,77 & 8,51 & 2,47 \\
\hline Jaken & $6.781,19$ & $1.898,73$ & 569.62 & 267,99 & 37,52 & 10,88 \\
\hline Batangan & 40,76 & 11,41 & 3.42 & 0,00 & 0,00 & 0,00 \\
\hline Juwana & 39,89 & 11,17 & 3.35 & 0,00 & 0,00 & 0,00 \\
\hline Jakenan & 39,89 & 11,17 & 3.35 & 353,33 & 49,47 & 14,35 \\
\hline Pati & 473,07 & 132,46 & 39.74 & 0,00 & 0,00 & 0,00 \\
\hline Gabus & 97,56 & 27,32 & 8.20 & 0,00 & 0,00 & 0,00 \\
\hline Margorejo & $34.252,87$ & $9.590,80$ & 2877.24 & 0,00 & 0,00 & 0,00 \\
\hline Gembong & $118.530,73$ & $33.188,60$ & 9956.58 & 0,00 & 0,00 & 0,00 \\
\hline Tlogowungu & $125.810,37$ & $35.226,90$ & 10568.07 & 0,00 & 0,00 & 0,00 \\
\hline Wedarijaksa & $3.914,79$ & $1.096,14$ & 328.84 & 0,00 & 0,00 & 0,00 \\
\hline Trangkil & $21.972,48$ & $6.152,29$ & 1845.69 & 0,00 & 0,00 & 0,00 \\
\hline Margoyoso & $54.111,06$ & $15.151,10$ & 4545.33 & 0,00 & 0,00 & 0,00 \\
\hline Gunungwungkal & $79.807,04$ & $22.345,97$ & 6703.79 & 0,00 & 0,00 & 0,00 \\
\hline Cluwak & $113.502,62$ & $31.780,73$ & 9534.22 & 0,00 & 0,00 & 0,00 \\
\hline Tayu & $20.837,58$ & $5.834,52$ & 1750.36 & 0,00 & 0,00 & 0,00 \\
\hline Dukuhseti & $14.002,47$ & $3.920,69$ & 1176.21 & 0,00 & 0,00 & 0,00 \\
\hline Kabupaten Pati & $611.584,75$ & $171.243,73$ & 51373.12 & $1.649,60$ & 230,94 & 66,97 \\
\hline
\end{tabular}

Sumber: Pengolahan Data (2013)

Produksi ubi jalar di Kabupaten Pati $1.649,60$ ton. Produksi ubi jalar yang digunakan untuk pangan hanya sebagian. Menurut Deptan (2007), produksi ubi jalar yang digunakan untuk pangan memiliki nilai konversi 0,14 (14\%), selebihnya untuk keperluan lain yang tidak terkait langsung dengan ketersediaan pangan masyarakat. Ketersediaan pangan terkait dengan produksi ubi jalar dapat dikalkulasi dengan menggunakan rumus :

$\mathrm{UJ}_{\text {net }}=\mathrm{UJ} \times \mathrm{C}$

$\mathrm{UJ}_{\text {rkn }}=\mathrm{UJ}_{\text {net }} \times 0,29$

Keterangan :

$\mathrm{UJ}_{\text {net }}=$ produksi neto ubi jalar
$\mathrm{UJ}=$ produksi bruto ubi jalar

$\mathrm{C}=$ faktor konversi ubi jalar $(0,14)$

$\mathrm{UJ}_{\mathrm{rkn}}=$ rasio konsumsi normatif kalori ubi jalar

$0,29=$ ubi jalar kalorinya setara 0,29 beras

Produksi neto ubi jalar terkait dengan pangan masyarakat harus dikonversi nilai kalorinya terhadap nilai kalori beras. Nilai rasio konsumsi normatif kalori ubi jalar (ekuivalen) terhadap beras sebesar 0,29 (29\% dari nilai kalori beras).

Produksi ubi jalar bruto (UJ) di Kabupaten Pati sebesar 1.649,60 ton, maka produksi neto ubi jalar $\left(\mathrm{UJ}_{\text {net }}\right)$ sebesar 230,94 ton yang berasal dari $1.649,60$ ton kali 0,14. Oleh karena itu, ketersediaan 
pangan masyarakat dari ubi jalar setara dengan kalori 66,97 ton (beras) yang berasal dari 230,94 ton kali 0,29.

\section{Produksi Neto Pangan Komposit dan Perkapita Pangan Per Hari}

Produksi neto pangan pokok merupakan produksi komposit dari ketersediaan bersih beras, jagung, ubi kayu dan ubi jalar. Menurut Deptan (2007), produksi neto pangan pokok komposit dihitung dengan menggunakan rumus :

$\mathrm{P}_{\text {food }}=\mathrm{R}_{\text {net }}+\mathrm{M}_{\text {net }}+\mathrm{UK}_{\text {net }}+\mathrm{UJ}_{\text {net }}$
Keterangan :

$\mathrm{P}_{\text {food }}=$ produksi neto pangan pokok

$\mathrm{R}_{\text {net }}=$ produksi neto beras

$\mathrm{M}_{\text {net }}=$ produksi neto jagung

$\mathrm{UK}_{\text {net }}=$ produksi neto umbi kayu

$\mathrm{UJ}_{\text {net }}=$ produksi neto umbi jalar

Secara kumulatif produksi neto pangan pokok di Kabupaten Pati sebesar 439.371,67 ton. Produksi neto pangan pokok terbesar berada di Kecamatan Sukolilo sebesar $67.544,36$ ton, disusul Kecamatan Kayen sebesar 39.968,43 ton. Perhatikan Tabel 4.

Tabel 4.

Ketersediaan Pangan Komposit dan Pangan Perkapita Per Hari di Kabupaten Pati

\begin{tabular}{|c|c|c|c|c|c|}
\hline \multirow{2}{*}{ Kecamatan } & Pangan (ton) & Pangan (gr) & Penduduk *) & Hari & Pangan/Kapita \\
\hline & $\mathbf{P}_{\text {food }}$ & $\mathbf{P}_{\text {food }}$ & & (1 th) & $\mathbf{F}$ \\
\hline Sukolilo & $67.544,36$ & 67.544 .360 .000 & 90.861 & 365 & 2.037 \\
\hline Kayen & $39.968,43$ & 39.968 .430 .000 & 83.678 & 365 & 1.309 \\
\hline Tambakromo & $28.846,11$ & 28.846 .110 .000 & 57.996 & 365 & 1.363 \\
\hline Winong & $22.721,42$ & 22.721 .420 .000 & 69.600 & 365 & 894 \\
\hline Pucakwangi & $25.777,08$ & 25.777 .080 .000 & 56.804 & 365 & 1.243 \\
\hline Jaken & $18.641,80$ & 18.641 .800 .000 & 49.165 & 365 & 1.039 \\
\hline Batangan & $9.273,88$ & 9.273 .880 .000 & 43.905 & 365 & 579 \\
\hline Juwana & $4.692,37$ & 4.692 .370 .000 & 95.738 & 365 & 134 \\
\hline Jakenan & $26.645,63$ & 26.645 .630 .000 & 51.178 & 365 & 1.426 \\
\hline Pati & $13.898,60$ & 13.898 .600 .000 & 111.416 & 365 & 342 \\
\hline Gabus & $24.405,97$ & 24.405 .970 .000 & 66.525 & 365 & 1.005 \\
\hline Margorejo & $20.631,13$ & 20.631 .130 .000 & 60.494 & 365 & 934 \\
\hline Gembong & $16.181,79$ & 16.181 .790 .000 & 47.384 & 365 & 936 \\
\hline Tlogowungu & $19.983,61$ & 19.983 .610 .000 & 57.434 & 365 & 953 \\
\hline Wedarijaksa & $5.671,03$ & 5.671 .030 .000 & 65.677 & 365 & 237 \\
\hline Trangkil & $6.732,52$ & 6.732 .520 .000 & 63.285 & 365 & 291 \\
\hline Margoyoso & $13.901,74$ & 13.901 .740 .000 & 80.112 & 365 & 475 \\
\hline Gunungwung & & & & & \\
\hline kal & $16.510,60$ & 16.510 .600 .000 & 39.343 & 365 & 1.150 \\
\hline Cluwak & $19.811,27$ & 19.811 .270 .000 & 49.785 & 365 & 1.090 \\
\hline Tayu & $18.722,56$ & 18.722 .560 .000 & 72.901 & 365 & 704 \\
\hline Dukuhseti & $12.840,54$ & 12.840 .540 .000 & 60.375 & 365 & 583 \\
\hline Kabupaten & & 439.371 .670 .00 & & & \\
\hline Pati & $439.371,67$ & 0 & 1.373 .656 & 365 & 876 \\
\hline
\end{tabular}

Sumber: Pengolahan Data (2013)

Ketersediaan pangan perkapita dihitung dengan komponen produksi neto pangan pokok (gram), jumlah penduduk dan hari setahun. Ketersediaan pangan perkapita dihitung dengan rumus :

$\mathrm{F}=\mathrm{P}_{\text {food }}:\left(\mathrm{t}_{\mathrm{pop}} \times 365\right)$
Keterangan :

$\mathrm{F}=$ ketersediaan pangan per kapita per hari

$\mathrm{P}_{\text {food }}=$ produksi neto pangan pokok (gram)

$\mathrm{t}_{\mathrm{pop}}=$ total penduduk

$365=$ jumlah hari setahun 
Ketersediaan pangan perkapita berguna untuk mengetahui kondisi status pangan di suatu kawasan. Konsumsi normatif pangan adalah jumlah pangan yang harus dikonsumsi per orang per hari untuk memperoleh kilo kalori energi. Standar kebutuhan kalori per hari per kapita adalah 2.200 Kkal dan untuk mencapai $50 \%$ kebutuhan kalori dari serealia, seseorang harus mengkonsumsi kurang lebih 300 gram serealia per hari.

Bila suatu kawasan memiliki ketersediaan pangan per kapita per hari lebih besar dari 300 gram maka kawasan itu masuk kategori surplus. Sebaliknya bila suatu kawasan memiliki ketersediaan pangan per kapita per hari lebih kecil dari 300 gram maka kawasan itu masuk kategori defisit. Ketersediaan pangan per kapita di Kabupaten Pati sebesar 876 atau sebesar $292 \%$ dari nilai per kapita pangan maka secara agregat masuk kategori surplus.

\section{Rasio Ketersediaan Pangan}

Rasio ketersediaan pangan merupakan rasio konsumsi normatif terhadap ketersediaan pangan. Konsumsi normatif pangan yang harus dikonsumsi per orang per hari untuk memperoleh kilo kalori energi, standar kebutuhan kalori per hari per kapita adalah 2.200 Kkal dan untuk mencapai 50\% kebutuhan kalori dari serealia maka seseorang harus mengkonsumsi kurang lebih 300 gram serealia per hari (Deptan, 2007). Rasio ketersediaan pangan dapat dihitung dengan menggunakan rumus :

$\mathrm{I}_{\mathrm{AV}}=\mathrm{C}_{\text {norm }}: \mathrm{F}$

Keterangan :

$\mathrm{I}_{\mathrm{AV}}=$ rasio ketersediaan pangan

$\mathrm{F}=$ ketersediaan pangan per kapita per hari

$\mathrm{C}_{\text {norm }}=$ konsumsi normatif (300 gram)

Perhitungan tersebut dapat digunakan untuk mengetahui kondisi ketersediaan pangan di suatu kawasan surplus atau defisit. Pucakwangi misalnya, produksi pangan per kapita sebesar 1.243 gram, bila konsumsi normatif 300 gram maka rasio konsumsi sebesar 0,241 atau setara dengan $24,1 \%$, atau produksi pangan sebesar 414,3\% dari kebutuhan konsumsi penduduk di kawasan itu.

Berdasarkan perhitungan, kondisi rasio ketersediaan pangan di Kabupaten Pati ditunjukkan pada Tabel 5.

Kebutuhan normatif konsumsi pangan pokok di Kabupaten Pati hanya $150.469,75$ ton $(34,2 \%)$ dari total produksi $439.371,67$ ton. Selebihnya 288.901,92 ton merupakan surplus produksi pangan pokok yang dapat disimpan untuk ketersediaan cadangan pangan. Dengan kata lain, produksi pangan di Kabupaten Pati 2,92 kali (292\%) dari kebutuhan konsumsi normatif. 
Tabel 5.

Rasio Ketersediaan Pangan di Kabupaten Pati

\begin{tabular}{lrrrrl}
\hline \multicolumn{1}{c}{ Kecamatan } & $\begin{array}{c}\text { Konsumsi } \\
\mathbf{C}_{\text {norm }}\end{array}$ & $\begin{array}{r}\text { Pangan/Kapita } \\
\mathbf{F}(\mathbf{g r})\end{array}$ & $\begin{array}{c}\mathbf{I}_{\mathbf{A V}=}= \\
\mathbf{C}_{\text {norm }}: \mathbf{F}\end{array}$ & $\begin{array}{c}\text { Invers } \mathbf{I}_{\mathbf{A V}}= \\
\mathbf{F}: \mathbf{C}_{\mathbf{n o r m}}\end{array}$ & $\begin{array}{c}\text { Status } \\
\text { Pangan }\end{array}$ \\
\hline Sukolilo & 300 & 2.037 & 0,147 & 6,790 & Surplus \\
Kayen & 300 & 1.309 & 0,229 & 4,363 & Surplus \\
Tambakromo & 300 & 1.363 & 0,220 & 4,543 & Surplus \\
Winong & 300 & 894 & 0,335 & 2,980 & Surplus \\
Pucakwangi & 300 & 1.243 & 0,241 & 4,143 & Surplus \\
Jaken & 300 & 1.039 & 0,289 & 3,463 & Surplus \\
Batangan & 300 & 579 & 0,518 & 1,930 & Surplus \\
Juwana & 300 & 134 & 2,234 & 0,447 & Defisit \\
Jakenan & 300 & 1.426 & 0,210 & 4,753 & Surplus \\
Pati & 300 & 342 & 0,878 & 1,140 & Rentan \\
Gabus & 300 & 1.005 & 0,298 & 3,350 & Surplus \\
Margorejo & 300 & 934 & 0,321 & 3,113 & Surplus \\
Gembong & 300 & 936 & 0,321 & 3,120 & Surplus \\
Tlogowungu & 300 & 953 & 0,315 & 3,177 & Surplus \\
Wedarijaksa & 300 & 237 & 1,268 & 0,790 & Defisit \\
Trangkil & 300 & 291 & 1,029 & 0,970 & Defisit \\
Margoyoso & 300 & 475 & 0,631 & 1,583 & Rentan \\
Gunungwungkal & 300 & 1.150 & 0,261 & 3,833 & Surplus \\
Cluwak & 300 & 1.090 & 0,275 & 3,633 & Surplus \\
Tayu & 300 & 704 & 0,426 & 2,347 & Surplus \\
Dukuhseti & 300 & 583 & 0,515 & 1,943 & Surplus \\
\hline Kabupaten Pati & 300 & 876 & 0,342 & 2,920 & Surplus \\
\hline Surat & & & &
\end{tabular}

Sumber: Pengolahan Data (2013)

\section{Pemilihan Lokasi Pembangunan Lumbung Pangan}

Lumbung pangan berfungsi untuk penyimpanan persediaan pangan cadangan. Pembangunan lumbung pangan sedikitnya memperhatikan tiga kriteria. Pertama, faktor surplus produksi pangan. Pemilihan lokasi pembangunan lumbung pangan yang dekat dengan kawasan surplus produksi pangan memiliki kelebihan efisiensi biaya transportasi dari masyarakat menuju tempat penyimpanan (lumbung pangan). Semakin besar nilai surplus produksi pangan, kawasan itu semakin baik untuk dibangun lumbung pangan guna meningkatkan efisiensi biaya transportasi, tenaga dan waktu. Uraian produksi pangan tersebut diatas akan digunakan sebagai dasar evaluasi nilai (skor) yang diberi kode (V1).
Kedua, pembangunan lumbung pangan agar mempertimbangkan kemudahan akses jalan dari berbagai arah. Semakin strategis dan mudah akses jalan kawasan, semakin baik untuk distribusi pangan ketika dibutuhkan. Berdasarkan eksistensi jaringan jalan utama di setiap kawasan akan diberikan nilai (skor) dengan diberi kode (V2).

Ketiga, pembangunan lumbung pangan agar mempertimbangkan keamanan dari reisiko bencana dalam konteks lokal daerah, bencana yang paling sering terjadi adalah bencana banjir. Tingkat kerentanan banjir setiap kawasan dapat diidentifikasi dari kondisi geografis terutama dataran paling rendah dan ketinggian rerata dataran. Kondisi dataran geografis dalam studi ini diambil dari "Pati Dalam Angka" (BPS Kab. Pati, 2011). 
Semakin tinggi dataran, semakin kecil risiko banjir pada kawasan tersebut dan diberi skor dengan kode (V3).

Bila skor kawasan terkait rasio produksi terhadap konsumsi diberi kode (V1); skor kawasan terkait akses jalan distribusi (strategis) dijangkau ke kawasan sekitar diberi kode (V2); dan skor kawasan terkait risiko bencana banjir diberi kode (V3), maka besaran nilai komposit merupakan refleksi tingkat priotitas untuk dipilih sebagai tempat pembangunan lumbung pangan yang disajikan pada Tabel 6.

Tabel 6.

Komparasi Lokasi Pembangunan Lumbung Pangan di Kabupaten Pati

\begin{tabular}{|c|c|c|c|c|c|c|c|c|c|}
\hline \multirow{2}{*}{ Kecamatan } & \multirow{2}{*}{$\begin{array}{c}\text { Rasio } \\
\text { Produksi }\end{array}$} & \multirow[t]{2}{*}{ V1 } & \multirow{2}{*}{$\begin{array}{c}\text { Akses } \\
\text { Distribusi }\end{array}$} & \multirow[t]{2}{*}{$\mathbf{V} 2$} & \multicolumn{2}{|c|}{$\begin{array}{c}\text { Banjir } \\
\text { (Dataran) }\end{array}$} & \multirow[t]{2}{*}{ V3 } & \multirow{2}{*}{$\begin{array}{l}\text { Skor } \\
\text { Total }\end{array}$} & \multirow{2}{*}{$\begin{array}{c}\text { Nilai } \\
\text { Relatif }\end{array}$} \\
\hline & & & & & Low & $\begin{array}{c}\text { Rata } \\
(\mathbf{m})\end{array}$ & & & \\
\hline Sukolilo & 6,790 & 21 & 1 arah & 7 & 5 & 85,69 & 12 & 39 & 61,91 \\
\hline Kayen & 4,363 & 18 & 3 arah & 18 & 5 & 67,71 & 11 & 47 & 74,60 \\
\hline Tambakromo & 4,543 & 19 & 2 arah & 11 & 13 & 79,22 & 16 & 46 & 73,02 \\
\hline Winong & 2,980 & 9 & 2 arah & 9 & 6 & 33,73 & 14 & 32 & 50,79 \\
\hline Pucakwangi & 4,143 & 17 & 1 arah & 2 & 15 & 51,15 & 17 & 36 & 57,14 \\
\hline Jaken & 3,463 & 14 & 3 arah & 13 & 15 & 30,05 & 18 & 45 & 71,43 \\
\hline Batangan & 1,930 & 6 & 2 arah & 12 & 2 & 9,00 & 2 & 20 & 31,75 \\
\hline Juwana & 0,447 & 1 & 3 arah & 20 & 2 & 4,86 & 1 & 22 & 34,92 \\
\hline Jakenan & 4,753 & 20 & 2 arah & 10 & 4 & 12,83 & 5 & 35 & 55,56 \\
\hline Pati & 1,140 & 4 & 4 arah & 21 & 4 & 11,83 & 10 & 35 & 55,56 \\
\hline Gabus & 3,350 & 13 & 3 arah & 14 & 2 & 3,92 & 3 & 30 & 47,62 \\
\hline Margorejo & 3,113 & 10 & 1 arah & 8 & 5 & 34,39 & 13 & 31 & 49,21 \\
\hline Gembong & 3,120 & 11 & 1 arah & 5 & 107 & 219,36 & 21 & 37 & 58,73 \\
\hline Tlogowungu & 3,177 & 12 & 1 arah & 6 & 38 & 172,87 & 19 & 37 & 58,73 \\
\hline Wedarijaksa & 0,790 & 2 & 3 arah & 19 & 2 & 10,50 & 4 & 25 & 39,68 \\
\hline Trangkil & 0,970 & 3 & 3 arah & 17 & 2 & 19,06 & 7 & 27 & 42,86 \\
\hline Margoyoso & 1,583 & 5 & 3 arah & 16 & 2 & 21,59 & 9 & 30 & 47,62 \\
\hline Gunungwungkal & 3,833 & 16 & 1 arah & 1 & 49 & 214,67 & 20 & 37 & 58,73 \\
\hline Cluwak & 3,633 & 15 & 1 arah & 4 & 6 & 205,00 & 15 & 34 & 53,97 \\
\hline Tayu & 2,347 & 8 & 3 arah & 15 & 2 & 12,90 & 8 & 31 & 49,21 \\
\hline Dukuhseti & 1,943 & 7 & 1 arah & 3 & 2 & 12,67 & 6 & 16 & 25,40 \\
\hline Kabupaten Pati & & 231 & & 231 & & & 231 & & \\
\hline
\end{tabular}

Sumber: Pengolahan Data (2013)

Berdasarkan nilai komposit yang tertera pada tabel di atas menunjukkan, pembangunan lumbung pangan terbaik bila diletakkan di Kecamatan Kayen dengan nilai komparasi relatif sebesar 74,60 yang berasal dari total skor (47) dibagi skor kriteria (63) dan dikalikan 100. Namun perlu disadari lokasi yang dipilih agar terbebas dari banjir. Kawasan ini memiliki tingkat produksi pangan relatif baik, letaknya strategis untuk distribusi ke kawasan sekitar dan kawasan yang berisiko terkena banjir hanya sebagian kecil. Prioritas berikutnya agar mempertimbangkan persebaran lokasi, khususnya untuk kawasan utara. 


\section{KESIMPULAN DAN SARAN}

\section{Kesimpulan}

Kabupaten Pati memiliki produksi pangan 2,92 kali kebutuhan normatif konsumsi. Dengan kata lain, kebutuhan konsumsi normatif Kabupaten Pati sebesar $34,2 \%$ dari total produksi pangan. Bila total ketersediaan pangan (produksi pangan pokok) sebesar 439.371,67 ton maka kebutuhan normatif konsumsi pangan pokok sebesar $150.469,75$ ton dan selebihnya 288.901,92 ton berpotensi untuk disimpan sebagai cadangan pangan.

Penyimpanan kelebihan produksi pangan dari konsumsi dapat dilakukan dengan pembangunan lumbung pangan. Kawasan kecamatan untuk pembangunan lumbung pangan terbaik, bila diletakkan di Kecamatan Kayen. Pembangunan lumbung pangan berikutnya agar mempertimbangkan persebaran lokasi, kawasan utara misalnya Tayu, kawasan ini strategis tetapi area yang dipilih agar berada di kawasan yang aman dari banjir dan mudah akses jalan.

\section{DAFTAR PUSTAKA}

Badan Pusat Statistik Kabupaten Pati. 2011. Pati Dalam Angka Tahun 2010. Pati.

Badan Pusat Statistik Kabupaten Pati. 2013. Pati Dalam Angka Tahun 2012. Pati.

Benjamin, O. C., C. A. Riordan. 1995. Comparing BP and ART II Neural Network Classifiers for Facility Location. Computers \& Industrial Engineering 28(1).

Departemen Pertanian. 2007. Peta Akses Pangan Pedesaan. Jakarta: Badan Ketahanan Pangan.

Falak, S., Sumarni. 2014. Kerugian Banjir Capai $\mathrm{Rp} \quad 1,65 \quad$ Triliun. (http://www.murianews.com/, diakses tanggal 7 Mei 2014).

Food Agricultural Organization. 1996. World Food Summit, tanggal 13 17 November. Roma: FAO.

Ghosh, A., F. Harche. 1993. Location Allocation Models in the Private Sector: Progress, Problems, and Prospects. Location Science 1(1).

Haigh, R. 1990. Selecting a US Plant Location: The Management Decision Process in Foreign Companies. Columbia Journal of World Business.

Kathawala, Y., H. Gholamnezhad. 1987. New Approach to Facility Location Decisions. International Journal of Systems Science 18(2).

Nawawi, H. 1995. Metode Penelitian Bidang Sosial. Yogyakarta: Gajah Mada University Press.

Undang-Undang Nomor 11 Tahun 2005 tentang Kovenan Internasional tentang Hak-Hak Ekonomi Sosial dan Budaya.

Undang-Undang Nomor 18 Tahun 2012 tentang Pangan.

United Nations. 1999. General Comment Nomor 12 Tahun 1999. New York: Komite Hak Ekonomi Sosial dan Budaya PBB.

Yang, J., H. Lee. 1997. AHP Decision Model for Facility Location Selection, Facilities 15(9): 241-254.

\section{BIODATA PENULIS}

Suroso, lahir 19 Maret 1966 di Kabupaten Pati Jawa Tengah. Magister Perencanaan Kota dan Daerah Universitas Gajah Mada. Bekerja di Kantor Penelitian dan Pengembangan Kabupaten Pati sebagai Peneliti Madya. 